\title{
Incidencia de la intervención urbana en el desarrollo turístico del Centro Histórico de Morelia, Michoacán
}

\author{
Incidence of urban intervention in the tourist development of the Historic Center of Morelia, Michoacán
}

Ana Karen Reyes- Aguilar ${ }^{1}$, Francisco Javier Rosas-Ferrusca ${ }^{1}$ y Carlos Alberto Pérez-Ramírez ${ }^{1}$

${ }^{1}$ Universidad Autónoma del Estado de México, Toluca, México

karenreyesaguilar@hotmail.com

\begin{abstract}
Resumen
Los centros históricos son parte del legado de la sociedad y cuentan, no sólo con valores estéticos, sociales, culturales y económicos, sino también representan una fuente de identidad social y constituyen un patrimonio invaluable en términos de los significados asociados a éste. Es por ello, que su gestión debe analizarse de manera diferente, especialmente cuando éstos se encuentran inscritos en la lista del Patrimonio Cultural de la Humanidad de la UNESCO. El artículo tiene como objetivo analizar el proceso de intervención urbana y desarrollo del turismo en el Centro Histórico de Morelia, Michoacán a partir del nombramiento como Patrimonio Cultural de la Humanidad, con la finalidad de identificar su incidencia en la dinámica de la realidad urbana. Se desarrolla en función de los elementos metodológicos propuestos por Troitiño Vinuesa (1992), soportado en un enfoque integral de los fenómenos y procesos de transformación urbana. Se demuestra que el Centro Histórico de Morelia ha sufrido diversas intervenciones urbanas, que han dado lugar a la valorización del sitio, el legado cultural y el desarrollo del turismo, mediante la apropiación del patrimonio, resultado de la implementación de políticas públicas neoliberales que permiten la mercantilización del espacio público.
\end{abstract}

Palabras clave: Política neoliberal, intervención urbana, Centro Histórico, turismo, patrimonio cultural de la humanidad.

\begin{abstract}
Historic centers are part of the legacy of society and have not only aesthetic, social, cultural and economic values, but also represent a source of social identity and constitute an invaluable heritage in terms of the meanings associated with it. Thus, the management of historic centers should be analyzed in a different way, especially when these are inscribed on the UNESCO World Cultural Heritage list. The objective of the article is to analyze the process of urban intervention and tourism development in the Historic Center of Morelia, Michoacán from the appointment as Cultural Heritage of Humanity, in order to identify its impact on the dynamics of urban reality. It is developed based on the methodological elements proposed by Troitiño Vinuesa (1992), supported by a comprehensive approach to urban transformation phenomena and processes. The article shows that the Historic Center of Morelia has undergone various urban interventions, which have led to the valorization of the site, the cultural legacy and the development of tourism, through the appropriation of heritage, the result of the implementation of neoliberal public policies that promote the commodification of public space.
\end{abstract}

Keywords: Neoliberal policy, urban intervention, Historic Center, tourism, cultural heritage of humanity 
Hablar de Centros Históricos resulta complejo debido a las diferentes ideologías que existen entorno a ellos desde una plataforma científica y entendiéndolos como parte de un proceso histórico de construcción y desarrollo en el cual experimentan múltiples transformaciones físicosociales y en donde su aprovechamiento suele estar determinado, comúnmente, por actividades productivas que la sociedad hace de él mediante la explotación de los recursos (naturales y culturales) existentes en éstos, a fin de estimular el desarrollo económico y social.

Desde finales del siglo XX los Centros Históricos han adquirido mayor valor dentro de las ciudades, especialmente como legado histórico y patrimonio cultural por su paisaje urbano-arquitectónico; no obstante, la política neoliberal, a través de procesos de intervención urbana, hace notar la verdadera realidad sobre dichos sitios, pues influye de manera directa sobre las decisiones políticas y económicas, tanto de los aspectos sociales como urbanos, lo que representa una constante amenaza por los cambios de uso de suelo y el incremento del sector comercial, principalmente encabezados por la actividad turística.

Ante ello, se observa un vínculo considerable entre la política neoliberal, la intervención urbana y la actividad turística en Centros Históricos, especialmente cuando éstos se encuentran inscritos en la lista de Patrimonio Cultural de la Humanidad, es decir, la promoción del turismo va de la mano con política de acumulación del capital mediante las transformaciones del espacio físico para ofertar servicios por medio de la iniciativa privada y local. No obstante, las modificaciones no siempre corresponden con el contexto de la ciudad misma, en ciertos momentos obedecen a intereses de particulares, lo que repercute en el sector social. De esta manera, se parte del supuesto que los procesos de intervención urbana, con base a los principios de política neoliberal, propician el desarrollo turístico en el Centro Histórico de Morelia, inscrito en la lista de Patrimonio Cultural de la Humanidad desde 1991.

El artículo tiene como objetivo analizar el proceso de intervención urbana y desarrollo del turismo en el Centro Histórico de Morelia, Michoacán (México) a partir del nombramiento como Patrimonio Cultural de la Humanidad, con la finalidad de identificar su incidencia en la dinámica de la realidad urbana. El documento se estructura a partir de antecedentes acerca de la política neoliberal como factor influyente de procesos de intervención urbana, el turismo en Centros Históricos y Patrimonio Cultural de la Humanidad, posteriormente se detalla la metodología empleada para el desarrollo de la investigación, con base a las aportaciones de Troitiño Vinuesa (1992) que destaca los pilares para el análisis de la intervención urbana y desarrollo turístico en Centros Históricos, con base en ellos, se presentan los resultados y conclusiones de la investigación.

\section{Política neoliberal factor influyente de procesos de intervención urbana}

La intervención urbana en los Centros Históricos y el desarrollo del turismo, se ha expandido en las últimas décadas en el marco del neoliberalismo, como corriente económica cuya visión radica en el liberalismo clásico asociado con políticas que implican apoyar la liberación de la economía, mediante el libre comercio, la reducción del gasto público e impuestos, además de promover la intervención del Estado en la sociedad y economía a favor del sector privado.

En este sentido, la incursión de las políticas neoliberales ha tenido un impacto sobre la realidad urbana de los Centros Históricos, pues los cambios políticos producidos a partir de la década de 1970, han transformado significativamente la forma de construir las ciudades, señal que esta política surge como respuesta a una serie de factores de la acumulación del capital y el debilitamiento de los poderes fácticos, provocando en el urbanismo una forma de mercantilización y de estabilidad de las clases hegemónicas, a partir del "embellecimiento" y la construcción social del espacio público, entendiendo éste como lugar de identidad, percepción, recreación, consumo e interacción social, dando lugar a la acumulación del capital a partir de nuevas formas urbanas como los proyectos de renovación urbana y los grandes centros comerciales (Filipe Narciso, 2013; Theodore, Peck y Brenner, 2009; Sager, 2011).

Rodríguez, Devalle y Ostuni (2013) mencionan que las ciudades neoliberales predominan en el ámbito global y se caracterizan porque la mayoría de sus componentes son objeto de negocio y especulación, en el marco de una mercantilización expandida, que produce efectos globales de "urbanización por desposesión". En este sentido, las 
políticas urbanas se despliegan en un escenario donde coexisten dificultades crecientes en amplios sectores sociales para concretar el acceso a la centralidad urbana, a la vez que se experimentan globalmente los efectos sostenidos de la dinámica del capital inmobiliario, que ha modificado radicalmente la territorialidad urbana.

Hoy en día, las políticas neoliberales continúan influyendo fuertemente en la intervención de las ciudades, mediante la mercantilización del espacio, y el diseño de los Centros Históricos de acuerdo a las necesidades del mercado, en este sentido, los Centros Históricos en México se orientan al mercado turístico, comercial e inmobiliario donde se observa la apropiación de los bienes materiales heredados del pasado para la implementación de productos y servicios, generalmente privados, que despojan a los pequeños comerciantes de su libertad de trabajo, conduciéndolos al trabajo informal en su propio espacio. Así las políticas neoliberales han impactado sobre la realidad urbana y la forma de construir e intervenir las ciudades.

De esta forma, la intervención urbana contempla acciones de rehabilitación como la puesta en valor de espacios públicos y privados, la renovación y mejoramiento de infraestructuras y equipamiento, la atención de la imagen urbana, restauración del patrimonio edificado $y$, en algunos casos, la inserción de nuevas edificaciones, además de un intento de describir, explicar y controlar los cambios que traerá el tiempo a fin de generar estrategias que permitan la correcta y efectiva implementación de lineamientos. Pero, además, se trata de encontrar las relaciones modificables tanto en el entorno urbano construido, como en los aspectos intangibles del territorio (Gurovich, 2002; López Valencia y López Bernal, 2012; Luna Martello, 2015). Troitiño Vinuesa (1992), considera que la intervención urbana, así como el sentido de las transformaciones, son fenómenos cambiantes en función de intereses económicos, valoraciones culturales o estereotipos profesionales. Es una realidad dinámica donde los problemas de reorganización interna del espacio urbano como, renovación, remodelación o rehabilitación, que han estado presentes siempre, se realizan de forma interior.

Con base en lo anterior, se aprecia que la política neoliberal urbana, se orienta hacia el mejoramiento de los servicios básicos y dotación de infraestructura en los asentamientos humanos y espacios públicos, con especial atención a los sectores comerciales como parte de la mercantilización del uso de suelo y la acumulación del capital, lo que sigue constituyendo un reto tanto para las instituciones correspondientes como para la ciudadanía que lo demanda, por lo que es posible comprender los alcances de la intervención urbana en el contexto del modelo neoliberal, caracterizado como un proceso mediante el cual se llevan a cabo actividades de regeneración y modificación del espacio físico, con la finalidad de cubrir necesidades requeridas en cierto periodo de tiempo y por algún sector público, privado o social específico.

\section{Configuración de Centros Históricos: turismo versus conservación}

Los centros históricos son espacios fundacionales, conservan características morfológicas particulares, confieren identidad y cohesión social, concentran un patrimonio cultural, material e inmaterial invaluable $y$ expresan la herencia de generaciones anteriores; su principal rasgo de identidad lo constituye la continuidad de las estructuras urbanísticas y arquitectónicas que se observa en el espacio público, formado a partir de la secuencia articulada de calles y plazas definiendo una cuadrícula adaptada a las condiciones geográficas que modela la imagen urbana de las estructuras de cada lugar; son sitios valorados económica y socialmente lo que provoca una constante tensión entre su conservación y la necesidad de generar un desarrollo sustentable que permita lograr su puesta en valor mediante acciones de revitalización para que se aproveche la urbanización existente y se contenga el tejido social y la vida cotidiana (Gil y Briseño, 2005; Pérez Medina y Torres Pérez, 2016; Ziccardi, 2016).

La irrupción de las actividades turísticas y de las prácticas de ocio en las zonas centrales de las ciudades históricas, constituyen un factor de atracción importante para el turismo, sin embargo no siempre se reconoce que la dinamización económica a partir de la intervención urbana, en equipamientos o infraestructuras culturales, tiene importantes implicaciones físicas y socioeconómicas, debido a que el turismo es una actividad de naturaleza transversal que permeabiliza campos diversos de la vida económica y social. Por ello resulta imprescindible interpretar el turismo en el marco de la 
dinámica actual de las sociedades y los territorios, así como definir con claridad el papel que los centros históricos desempeñan en las complejas estructuras urbanas y territoriales del Siglo XXI, especialmente cuando éstos se convierten en una "burguesía cultural" que se apropia de un capital cultural histórico colectivamente elaborado, relacionado con los cambios sociales, culturales y con las debilidades de unas políticas urbanísticas o de protección patrimonial donde apenas se ha prestado atención a las cuestiones sociales y funcionales (Troitiño Vinuesa y Troitiño Torralva, 2016).

De acuerdo con Delgadillo Polanco (2009), Ormindo de Azevedo (2009), Ponce Herrero (2018), Navarrete Escobedo (2017) y Ortiz Álvarez, Tamayo Pérez, González Sánchez y Villaseñor Franco (2017), el turismo es una de las actividades económicas más importantes en el ámbito global, siendo el patrimonio histórico, las ciudades históricas, las ruinas de ciudades antiguas y otros sitios arqueológicos uno de los nuevos productos turísticos que, promovidos por políticas neoliberales a través de gobiernos y empresarios, presenta mayor impacto por las prácticas turísticas contemporáneas, generando conflictos entre su aprovechamiento, la salvaguarda y dicha actividad, por lo que Zúñiga Bravo (2014) y González-Hernández (2009), afirman que el turismo, además de actuar como un vehículo para transformar el medio físico, social y cultural de los territorios, debe constituir una reconfiguración o reorganización, a partir de una política de rehabilitación, en los centros históricos con base en el contenido natural y cultural, como un producto que se puede ofertar de tal manera que fomente la articulación de nuevas regiones socio-económicas con una organización interna y externa, incidiendo en la valoración del patrimonio histórico-cultural a partir de la creación de nuevos destinos turísticos que estimulen el crecimiento de dicha actividad.

En este sentido, Cejudo Collera (2017) y Cerletti (2017) consideran que es necesario crear instrumentos $y$ estímulos que regulen y prohíban los cambios de uso de suelo en dichos sitios, además de promover una mejora en la actividad turística, con la finalidad de preservar el valor histórico y cultural de los edificios, la huella y la memoria de los habitantes en ellos impresos y, para revertir la tendencia al despoblamiento, situación generada por el creciente interés de llevar a cabo proyectos e inversiones en torno a la renovación y transformación de los Centros
Históricos en espacios privilegiados para la recreación, mediante el fomento de actividades comerciales y de servicios, además de la oferta cultural y gastronómica como producto del impulso de un capital turístico, destino ineludible de los cascos históricos cuando se transforman en áreas atractivas, derivado de la política neoliberal.

Sin duda los Centros Históricos constituyen un elemento esencial en el sistema urbano, representan aspectos económicos, simbólicos y culturales por lo que se encuentran sometidos a constantes procesos de intervención y renovación urbana con el fin de generar beneficios tanto económicos como socio-culturales a partir de la actividad turística, de ahí el interés por mejorar sus condiciones pues su aprovechamiento simboliza un conjunto de oportunidades como estrategia para fomentar la permanencia de grupos sociales, económicos y políticos que promuevan su conservación y permanencia en el tiempo, ya que se vislumbran como una fuente activa para el desarrollo económico y socio-cultural.

\section{Elementos del Patrimonio Cultural de la Humanidad y Centros Históricos}

En 1972 surge la Convención para la Protección del Patrimonio Mundial Cultural y Natural, encargada de identificar y promover la conservación de los bienes inestimables e irremplazables de las naciones, siendo la Organización de las Naciones Unidas para la Educación, la Ciencia y la Cultura (UNESCO), el organismo encargado de su gestión respecto a los recursos naturales y valores culturales; otorga el título de Patrimonio Cultural de la Humanidad (PCH) a aquellos sitios específicos que cuentan con elementos de importancia cultural o natural excepcional como bosque, lago, desierto, edificación, complejo arquitectónico, ruta cultural, paisaje cultural o ciudad, entre otros, con el propósito de preservar y dar a conocer su importancia para la humanidad; cuenta con un catálogo de 1.092 sitios que poseen dicha distinción, distribuidos en 167 países, entre ellos México, de los cuales 845 son culturales, 209 naturales y 38 mixtos (UNESCO, 2017a).

EI Patrimonio Cultural es definido por la UNESCO como: a) tradicional, contemporáneo y viviente que incluye tradiciones heredadas del pasado y usos rurales y urbanos contemporáneos como el patrimonio cultural inmaterial; b) integrador, comparte expresiones de 
patrimonio cultural de distintos grupos humanos, adaptadas por pueblos que han emigrado y las transmiten de generación en generación contribuyendo a la construcción de identidad y continuidad; c) representativo, el patrimonio cultural se valora por su exclusividad o valor excepcional y florece en las comunidades a partir de los conocimientos de las tradiciones, técnicas y costumbres que se transmiten de generación en generación y; d) basado en la comunidad, el patrimonio cultural sólo puede serlo si es reconocido como tal por las comunidades, grupos o individuos que lo crean, mantienen y transmiten (UNESCO, 2017c). De esta forma, el patrimonio cultural remite a las relaciones que los pueblos y sus habitantes tienen con su pasado, identidad e historia local o nacional, abarca un conjunto de objetos tangibles e intangibles con diversos significados, usos y prácticas colectivas (Armenta, 2009).

De acuerdo con Campos Gutiérrez (2017), el concepto de patrimonio cultural de los Centros Históricos ha pasado a ser un producto de mercado pues, actualmente, depende más del interés de los visitantes que de los propios habitantes ya que se encuentra inmerso en un contexto social destinado al consumo por influencia de la política neoliberal encargada de la modificación de zonas patrimoniales de las ciudades; en esta lógica, es necesario su estudio particular con el fin de comprender los procesos en torno a su conservación y transformación, del tal manera que se reconozca como un elemento relevante en la configuración de la identidad y en la cohesión social (Mercado López, 2017).

Con base en lo anterior, se considera que la inscripción de los Centros Históricos en la lista de Patrimonio Cultural de la Humanidad sirve como instrumento de regulación para su conservación, no obstante, es necesario vislumbrar a la actividad turística como una estrategia que contribuye a la preservación patrimonial y al desarrollo local de las comunidades anfitrionas, en donde la prioridad es preservar el patrimonio cultural y el legado urbano histórico como pieza fundamental en el sistema urbano.

\section{Metodología}

La presente investigación tiene como soporte metodológico la técnica documental, por lo que se consultaron diversas fuentes bibliográficas especializadas en política neoliberal, intervención urbana, patrimonio y turismo. Con ello, se elaboró un esquema para abordar el análisis de la política neoliberal en la intervención urbana y el desarrollo turístico en Centros Históricos a partir de la identificación de variables que constituyen las categorías del objeto de estudio.

De igual forma, se revisaron documentos de dependencias oficiales como la UNESCO, para la obtención de información de ciudades patrimoniales y su conceptualización, la Organización Mundial del Turismo (OMT) para precisar conceptos y datos respecto al turismo, del Instituto Nacional de Estadística y Geografía (INEGI), a través de datos geográficos, el Instituto Nacional de Antropología e Historia (INAH), de la Secretaría de Turismo (SECTUR), Ayuntamiento de Morelia, particularmente de la Regiduría de Desarrollo Urbano y Medio Ambiente de Morelia, Secretaría de Bienestar, entre otras.

Con base en esta revisión, se integró un esquema general para el análisis del proceso de intervención urbana y desarrollo del turismo en el Centro Histórico de Morelia, utilizando tres variables centrales:

a) Política urbana, que deriva en la intervención urbana a través de la asistencia de problemáticas como satisfacer necesidades o demandas para mejorar la calidad de vida de los habitantes, mediante la implementación de planes y programas de desarrollo;

b) Patrimonio Cultural de la Humanidad, considera los criterios de la UNESCO para la preservación de los centros Históricos que cuentan con la distinción;

c) Turismo, descrito a partir de los procesos y acciones que se lleven a cabo en el centro histórico enfocados en la actividad turística y que permita la conservación del patrimonio.

Asimismo, se retoman las aportaciones de Troitiño Vinuesa (1992) con el propósito de llevar a cabo el análisis sobre intervención urbana y desarrollo turístico en el Centro Histórico de Morelia, pues no sólo reconoce las intervenciones físicas sino también las transformaciones simbólicas y especulaciones histórico-artísticas o rehabilitaciones socio-culturales locales, destacando las dimensiones funcionales y sociales de recuperación, considerando que en la dinámica urbana es necesario conjugar diversas escalas y categorías analíticas en el 
marco de una perspectiva histórica, ya que se vislumbra a la ciudad como una realidad dinámica y cambiante con forma, organización, funcionamiento y significado, aspectos que varían según los ciclos o coyunturas históricas. Además, destaca la necesidad de comprender la lógica de los procesos económico-sociales, con la finalidad de identificar las claves de la dinámica urbana y la realidad actual como proceso previo para formular propuestas de conservación o de transformación.

El planteamiento de Troitiño Vinuesa (1992) en materia de centros históricos, resulta fundamental, ya que los siguientes pilares constituyen soportes básicos para su estudio (ver Figura 1):

- Perspectiva histórica, modelo interpretativo de la dinámica de los centros históricos respecto a las políticas urbanas de recuperación: refiere a un espacio histórico cuya organización y patrimonio edificado conserva las diferentes formaciones sociales.

- Valoración del legado histórico-cultural de la ciudad: apreciación social del ámbito cultural de la ciudad como memoria colectiva de la sociedad, para formular políticas de recuperación adecuadas al contexto actual acordes con el pasado que merece ser conservado.

- Visión dinámica de la realidad urbana: indagando sobre la dimensión espacial de los procesos económico-sociales, que permite acercarse a los problemas actuales con perspectiva global, para dar respuestas a los problemas y necesidades del presente, con el propósito de superar las fracturas y los bloqueos entre las fases propositivas y las de gestión, entre la teoría y la práctica.

Al retomar los pilares considerados por Troitiño Vinuesa (1992), se busca comprender los valores arquitectónicos, urbanísticos y culturales del pasado, además de los problemas y necesidades entre las estructuras morfológicas, sociales, culturales y económicas, en cuanto a realidades urbanas vivas y partes integrantes de la ciudad actual, especialmente en los Centros Históricos, que constituyen una realidad donde a lo largo de la historia se han producido equilibrios y rupturas, mismos que se desencadenan a partir de las políticas urbanas, la declaratoria de Patrimonio Cultural, la participación social y el turismo.

La Figura 1 muestra los tres pilares de análisis para explicar la relación entre política neoliberal e intervención urbana y su incidencia en el desarrollo del turismo en el Centro Histórico de Morelia. De esta forma, el pilar de procesos espacio-temporales aporta la caracterización del espacio histórico, el patrimonio edificado y las formas de organización social antes de la declaratoria de $\mathrm{PCH}$, es decir, describe cómo era el CHM en el pasado, con la finalidad de comprender su dinámica actual. Por otra parte, y vinculado con lo anterior, el pilar de valoración del legado histórico-cultural, alude a la apreciación cultural de la ciudad como remembranza colectiva de la sociedad, con el fin de formular políticas de recuperación adecuadas a las necesidades sociales y del espacio físico para conservar el patrimonio. Respecto al pilar de dinámica de la realidad urbana, explica las formas de apropiación del espacio físico y el patrimonio mediante la implementación de políticas neoliberales y los procesos de intervención urbana del CHM, reconociendo los procesos de mercantilización de dicho espacio, así como el cambio en el sentido y rol que representa dentro del sistema urbano y social. 


\section{Figura 1}

Pilares para el análisis de intervención urbana y desarrollo turístico en Centros Históricos

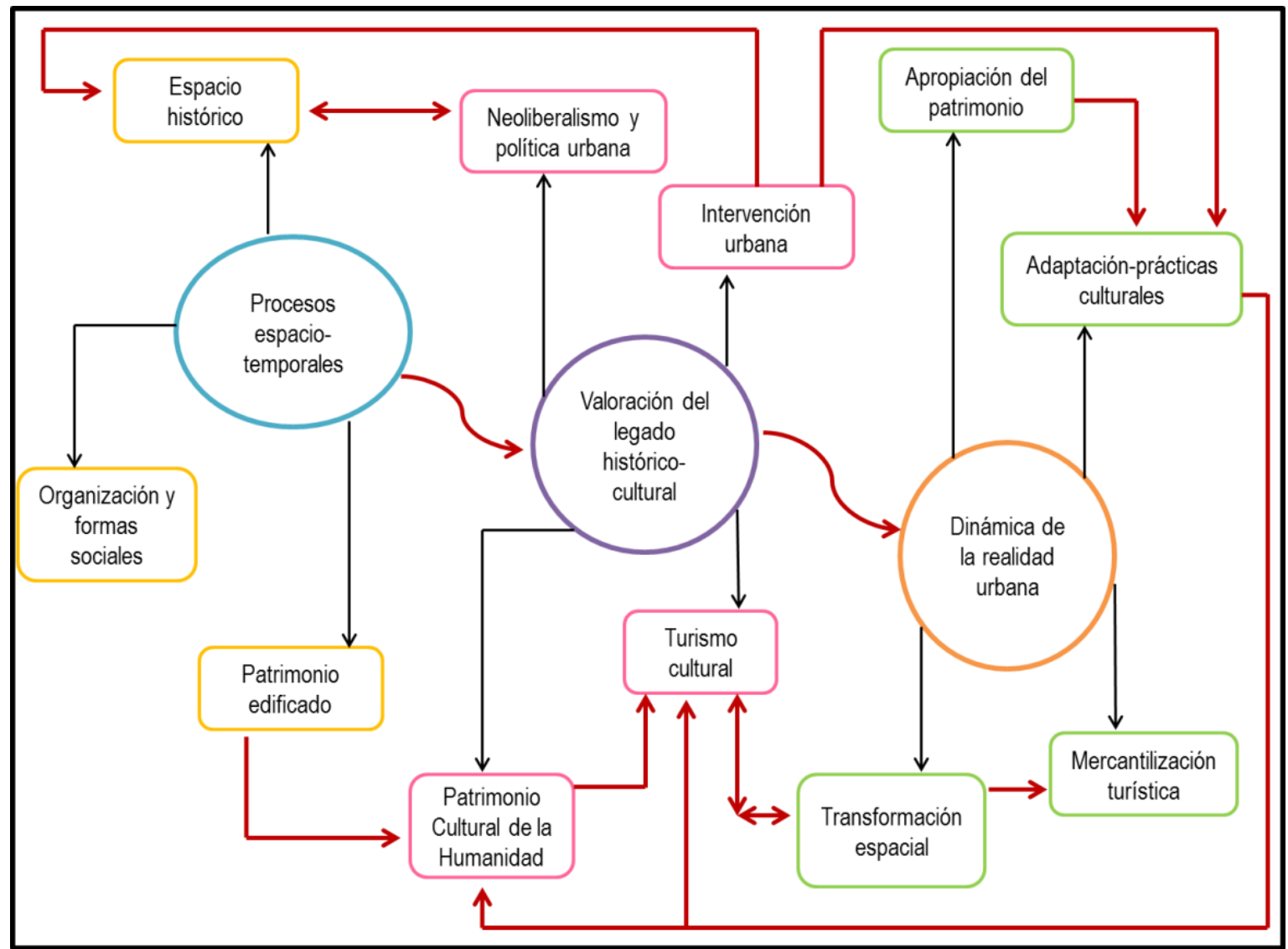

Fuente. Elaboración propia con base en Troitiño Vinuesa (1992).

\section{Resultados}

\section{Procesos espacio-temporales en Morelia}

La ciudad de Morelia se fundó en 1541 con el nombre de "Nueva Ciudad de Michoacán", posteriormente cambió a "Valladolid" en 1578, pero fue en 1828 cuando recibió el nombre de "Morelia" en honor a José María Morelos y Pavón (CONACULTA, 2017). Se ubica en la región oeste de México, en el Estado de Michoacán de Ocampo el cual limita al norte con los Estados de Jalisco y Guanajuato, al este con el Estado de México, al sur con Guerrero y al oeste con el océano Pacífico; el Centro Histórico de Morelia se sitúa entre los $19^{\circ} 42^{\prime} 16^{\prime \prime}$ de latitud norte, $101^{\circ} 11^{\prime} 30^{\prime \prime}$ de longitud oeste, presenta una altitud de 1,951 metros sobre el nivel del mar (msnm) (ver Figura 2); colinda al norte con los municipios de Huaniqueo, Chucándiro, Copándaro y Tarímbaro; al este con Tarímbaro, Charo, Tzitzio y Madero; al sur con Madero, Acuitzio, Pátzcuaro y Huiramba; al oeste con Huiramba, Lagunillas, Tzintzuntzan, Quiroga, Coeneo y Huaniqueo (INEGI, 2009). 


\section{Figura 2}

\section{Polígono del Centro Histórico de Morelia}

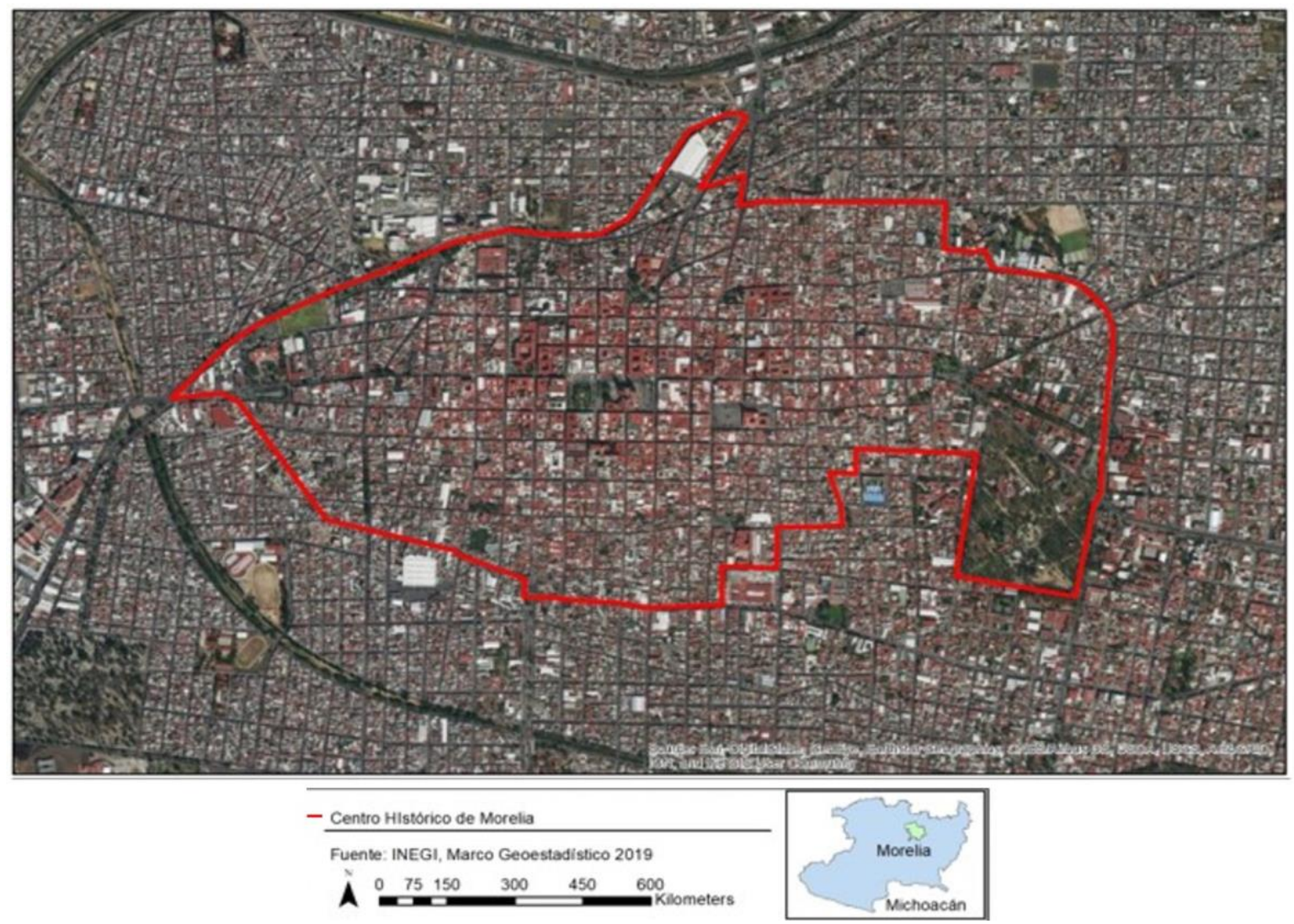

Fuente. Elaboración propia.

El Centro Histórico de Morelia sigue representado un ejemplo de planificación urbanística en la que se fusionan los conceptos del Renacimiento Español con la experiencia mesoamericana; su traza reticular responde a criterios establecidos por la Corona Española, adaptada a la configuración natural de la colina (Jiménez Izarraraz, Bernal Astorga, Aguilera Soria y Romo Careaga, 2016). Su historia arquitectónica se observa en sus más de 200 edificios históricos construidos con piedra de cantera que ponen de manifiesto la fusión del espíritu medieval con elementos renacentistas, barrocos y neoclásicos (UNESCO, 2017b).

Está constituido por 271 ha, 219 manzanas, 15 plazas y 1.113 monumentos, de los cuales 249 son de mayor importancia puesto que representan la historia arquitectónica del centro de la ciudad, constituyendo un conjunto considerado de gran valor debido a la armonía, calidad constructiva y unidad plástica que representan los diferentes estilos arquitectónicos, un continuo testimonio viviente de la historia de la arquitectura de México (Jiménez Izarraraz et al., 2016 y Rodríguez García, 2001).

Respecto a sus formas de organización histórica, se perfila hacia el año 1530 cuando los franciscanos evangelizaron a los habitantes, desplazando a la población local al norte de la ciudad dejando el terreno libre para la construcción de un monasterio y el desarrollo urbano con grandes obras arquitectónicas en el siglo XVIII. Era una ciudad de ricos propietarios de tierras, ganado y minas; albergaba tres Colegios a los que asistían jóvenes de todo el obispado y formaron las élites de la modernidad cristiana quienes, en la guerra de Independencia, lucharon a favor del movimiento. Después de la Revolución Mexicana, hubo una explosión demográfica la cual no fue paralela con el crecimiento urbano, generando diferentes niveles socioeconómicos, socioculturales y con una organización sociopolítica dividida en repúblicas de 
españoles y de indios, por lo que establecieron normas de convivencia de acuerdo a los usos y costumbres (Jiménez Izarraraz et al, 2016 y Zavala García, 2016).

Al inicio de la segunda mitad del Siglo XIX, se consolidó y modernizó el país con la Ley de Desamortización de Bienes Civiles y Eclesiásticos que produjo la incautación de los bienes de la Iglesia, algunos templos fueron vendidos, otros demolidos para abrir calles, otros se convirtieron en plazas y mercados, mientras que algunos colegios se destinaron para oficinas públicas, escuelas, cárceles y hospitales. El resultado arrojó otra mirada de la ciudad que permitió fortalecer el sentimiento de pertenencia, lo que contribuyó a la regulación administrativa de las condiciones de Protección y Conservación de Monumentos y Zonas Coloniales (Zavala García, 2016).

De esta manera, con la implementación de instrumentos jurídicos para la conservación de monumentos, a mediados del siglo XX, el 13 de diciembre de 1991, el Centro Histórico de Morelia fue inscrito en la lista del Patrimonio Cultural de la Humanidad de la UNESCO, debido a los 1.113 edificios catalogados como monumentos arquitectónicos de valor excepcional, de éstos 260 fueron señalados como relevantes por su valor histórico y arquitectónico, las características formales de edificación, armonía volumétrica, calidad constructiva, unidad plástica y diferentes estilos de construcción desarrollados a través de los siglos como testimonio de la historia arquitectónica de la nación (UNESCO, 2017b). La distinción obtenida incrementó el valor del sitio tanto para el sector sociocultural como para el económico, pues a raíz de ello se ideo como un nuevo mercado, apoyado en la implementación de políticas neoliberales, para la actividad turística y el comercio.

\section{Centro Histórico de Morelia, valoración del legado histórico-cultural}

El Centro Histórico de Morelia cuenta con diversos instrumentos jurídicos que resaltan la importancia del valor del paisaje urbano histórico que posee, pues su diseño y estructura urbana dio lugar a dos importantes declaratorias cuyo objetivo principal fue acrecentar el valor y la conservación del legado histórico, por una parte, en el ámbito nacional, en el año de 1990 obtuvo la declaratoria de Zona de Monumentos Históricos y posteriormente, y en 1991, fue inscrito en la lista del
Patrimonio de la UNESCO, distinciones que repercutieron en el sector social, económico y jurídico debido a los más de mil edificios señalados como relevantes por su valor histórico y arquitectónico, además de que ahí continua reflejándose la cultura y modos de vida de sus habitantes.

Ambas declaratorias propiciaron una serie de transformaciones entre las que destacaron la innovación del régimen de propiedad de diversos inmuebles y el control social y, por ende, la forma jurídica de proteger y conservar el Centro Histórico, siendo el Instituto Nacional de Antropología e Historia (INAH) la instancia encargada de su monitoreo. No obstante, la esencia del Centro respecto a su régimen político, religioso, cultural, económico y social, su organización física, calles, edificios, escuelas, el conjunto de costumbres y tradiciones, entre otros, está sujetos a disposiciones jurídicas que regulan su uso debido al valor histórico-cultural que representan.

Como parte de la gestión y políticas urbanas emitidas por las diversas administraciones posteriores a la declaratoria de Patrimonio, el Centro Histórico de Morelia fue sometido a diversos proyectos de intervención urbana con la finalidad de mejorar tanto la imagen de la ciudad como para salvaguardar el legado histórico-cultural, entre las intervenciones destacaron: el rescate y mejoramiento de plazas, jardines e inmuebles patrimoniales, mismos que se rehabilitaron mediante la restitución de aplanados alterados, el arbolamiento y puesta de vegetación en plazas y aceras, además del ordenamiento territorial visto, principalmente, en cuestiones de movilidad en calles primarias del Centro como la reubicación del comercio informal en vía pública, ordenamiento del transporte público, peatonalización de calles, entre otros aspectos.

La peatonalización, parcial o total, de diversas calles primarias del Centro Histórico, realizada entre los años 2015-2018 fue uno de los principales proyectos de intervención urbana que se llevaron a cabo con la finalidad de optimizar la movilidad tanto del transporte público como de vehículos particulares, además de contribuir a la disminución de emisiones contaminantes, que generan daños en edificaciones históricas y a la salud humana, y generar mayor seguridad a los transeúntes locales $y$ visitantes; el proyecto gustó tanto a los habitantes del sitio como a los turistas, nacionales y extranjeros, pues además de permitir la admiración del principal edificio religioso, es 
una calle que remonta a la historia por la convergencia de cada uno de sus elementos.

Por otra parte, se llevó a cabo el proyecto de iluminación de la Catedral de Morelia, monumento arquitectónico más emblemático, el cual consistió en el cambio de luminarias mismas que proyectarían diversas tonalidades de colores, a través del Programa de Desarrollo Regional Turístico Sustentable y Pueblos Mágicos otorgado por gobierno federal y estatal (SECTUR, 2017). La inauguración del proyecto dio lugar a diversas actividades artísticas y culturales que fueron disfrutadas por personas locales y turistas.

Dichas transformaciones permitieron que los habitantes lograran vislumbrar y valorar el legado histórico de la ciudad y generar un sentido de pertenencia e identidad social, a través del rescate de inmuebles, la continuación de costumbres y tradiciones celebradas en el Centro y la peatonalización de algunas calles, pues la mayoría de los habitantes se sienten orgullosos de ser originarios de Morelia y poder disfrutar y contribuir a la conservación del Centro Histórico, además de estar satisfechos con las iniciativas de políticas y gestión urbana respecto a la conservación del Patrimonio y poder compartirlo con la ciudadanía nacional y extranjera, esto se traduce en términos de que se les permite el disfrute del espacio público mediante el embellecimiento de la ciudad.

Si bien se consideró el conjunto arquitectónico, los monumentos, la traza y el paisaje urbano del Centro Histórico de Morelia para su inscripción a la lista del patrimonio, también se tomó en cuenta el aspecto cultural, representado, principalmente por sus procesos de evolución en la historia humana y los eventos o tradiciones vivas asociadas a creencias, obras artísticas y su cocina tradicional, mismas que detonan una importancia de carácter universal. Principalmente se valora la tradicional "Danza de los viejitos" y la representación de "pirekuas", ambas originarias del Estado de Michoacán, por otra parte, cuentan con diversos conocimientos culinarios, mismos que contemplan elementos básicos como el maíz, frijol, chile, tomate, aguacate, cacao, entre otros de no menor importancia; estos productos les permite generar alimentos únicos que han llevado a la gastronomía michoacana a ser parte del legado histórico y símbolo de identidad cultural y social.

Una de las costumbres y tradiciones de mayor relevancia es, en el ámbito nacional e internacional, la festividad de Día de Muertos realizada a finales del mes de octubre y principios de noviembre, esta celebración simboliza la muerte y el renacimiento, el ritual que se lleva a cabo logró el reconocimiento de la UNESCO en el año 2003, por lo que actualmente, se lleva a cabo en conjunto con diversos eventos en el Centro de Morelia tales como recorridos culturales entre calles y panteones cercanos, exposiciones, conciertos, talleres, y más, siendo el Festival Internacional de Cine de Morelia (FICM) un evento previo a la celebración de Día de Muertos, ya que está considerado como uno de los festivales cinematográficos más importantes en América Latina, lo que promueve la actividad turística en el contexto internacional.

En conjunto, el paisaje urbano y los diversos elementos culturales y sociales, han hecho del Centro Histórico y de la ciudad de Morelia en general, un excelente atractivo turístico, siendo el nombramiento de la UNESCO el que realzó, de manera paulatina, la actividad turística en este sitio, pues esto detonó un incremento de visitantes y obligó al sector empresarial a mejorar su desempeño y servicios, así como a los actores gubernamentales a generar políticas urbanas que garantizaran la seguridad e integridad económica y social, además de resguardar y conservar el patrimonio.

\section{Centro Histórico de Morelia: política neoliberal y realidad urbana}

Desde finales del siglo XX los Centros Históricos han adquirido mayor valor dentro de las ciudades, especialmente como legado histórico y patrimonio cultural por su paisaje urbano-arquitectónico, no obstante, la política neoliberal a través de la política pública, hace notar la verdadera realidad sobre dichos sitios, pues influye de manera directa sobre las decisiones políticas y económicas, tanto de los aspectos sociales como urbanos, lo que representa una constante amenaza por los cambios de uso de suelo y el incremento del sector comercial, encabezados, principalmente, por la actividad turística. 
En este sentido, el diseño urbano del Centro Histórico de Morelia así como el grado de conservación que presenta su arquitectura, le ha permitido preservar la distinción en el ámbito internacional por más de 25 años, no obstante del año 2000 en adelante, el legado histórico ha estado sujeto a diversos cambios, tanto positivos como negativos, especialmente en la disposición de los inmuebles urbanos y en el sector social, problemática que se le adjudica a la implementación de políticas urbanas de corte neoliberal que dan lugar a la especulación e intereses económicos derivados de la importancia que adquirió el sitio después de la declaratoria.

Respecto a las transformaciones físicas, el Centro Histórico empezó a sufrir diversas intervenciones urbanas, específicamente en los edificios históricos que pasaron de ser casa habitación, grandes casonas, conventos, haciendas e iglesias a hoteles, restaurantes, museos, tiendas de conveniencia, estacionamientos, centros de salud, instituciones educativas, entre otros, de tal manera que enmarcó una nueva centralidad ${ }^{1}$ en Morelia, regida por diversos procesos de intervención urbana en términos de especulación financiera, actualmente representada por el sector turístico, situación que deja de lado la importancia del legado histórico-cultural por inducirlo como un producto de mercado destinado al consumo.

Los diversos proyectos de intervención urbana que se han llevado a cabo para recuperar y conservar espacios públicos, la imagen urbana y para el crecimiento económico y la generación de empleos, también han sido aprovechados para favorecer la actividad turística en el cuadro principal del Centro Histórico y el entorno de la zona de monumentos. De esta manera, se trabajó en la limpieza y mejora de imagen del Acueducto y otras edificaciones, mediante el retiro de basura y flora nociva de banquetas que afectaban su visibilidad, posterior a ello, su mantenimiento se dio de manera progresiva con actividades de limpieza, fumigaciones y la revisión de circuitos eléctricos instalados para su iluminación como

${ }^{1}$ Al respecto, conviene apuntar que Carrión (2005), destaca que el centro histórico es el espacio público por excelencia y un objeto púbico del gobierno, lo que permite pensarlo como un proyecto de centralidad que retoma las raíces históricas y culturales de la ciudad que vincula el encuentro, las identidades y la cuestión cívica, y no únicamente un lugar parte del atractivo turístico, además de propiciar el cuidado y conservación en el tiempo.

Así mismo, se impulsó el rescate del Centro Histórico que consistió en la reubicación del comercio informal de los espacios urbanos, se dio espacio a vendedores de dulces y artesanías en el Mercado de Dulces esto por parte de los sectores conscientes del valor de la ciudad y con la finalidad de fortalecer el valor de la herencia cultural además, se otorgó un espacio restaurado que se convirtió en el actual mercado de antojitos (Aguilera Soria, 2016), situación que favoreció a empresas del sector privado, pues fueron quienes instalaron comercio en las inmediaciones de los edificios históricos, lo que provoco un cambio sustancial del uso de suelo y por ende la modificación de los inmuebles para adaptar los negocios.

La Central de Autobuses y las terminales de autobuses suburbanos y rurales fueron reubicadas con la finalidad de liberar el tránsito de unidades de transporte urbano y foráneo en el Centro Histórico, al mismo tiempo que se inició la peatonalización de diversas calles para brindar movilidad peatonal tanto a los habitantes locales como a turistas, dichos proyectos contemplan adecuaciones para personas con capacidades diferentes y adultos mayores, contribuyendo a promover la economía y mejorar la cultura con el propósito de reactivar la ciudad y constituir un mayor atractivo y disfrute del paisaje arquitectónico e histórico de la misma.

De esta manera, el Centro Histórico de Morelia se ofrece en el mercado turístico como un destino antiguo con variedad de actividades culturales como el Festival Internacional de Cine de Morelia, importante celebración en la que acuden actores internacionales y nacionales, con la finalidad de fomentar actividades culturales y turísticas; el Festival de Música de Morelia Miguel Bernal Jiménez, que promueve la enseñanza musical mediante exponentes de la música provenientes de todo el mundo; la Expo Feria Michoacán, con exposiciones gastronómicas, eventos culturales y deportivos, juegos mecánicos, palenque de gallos $y$ exposiciones ganaderas.

memorístico para sus habitantes. Para este autor, el centro histórico está lleno de simbolismos (debido a su centralidad y a su contenido histórico), de significaciones y de temporalidad para la sociedad, pues es aquí donde ésta se visibiliza y se representa; aspectos que sin duda es posible identificar en el caso del CHM. 
Adicionalmente, se ofrecen paseos por el área de monumentos, partiendo del primer cuadro del Centro Histórico, con la finalidad de apreciar la arquitectura y diseño de sus edificios como templos, casonas, monumentos, museos, plazas, parques y callejones de la ciudad, desde la fuente de las Tarascas, el acueducto, que aún conserva más de doscientos cincuenta arcos cubriendo casi mil setecientos metros, hasta el Bosque Cuauhtémoc que funciona como complejo monumental, recreativo y deportivo, el centro cultural, el Ex-convento del Carmen y los museos Regional Michoacano, de Arte Contemporáneo y arte virreinal; además de la basta gastronomía tanto en restaurantes como en pequeños comercios y el mercado; todos ellos reflejo de la amplia y diversa oferta turística.

Sin embargo, el proceso de transformación urbana que se generó a partir de la declaratoria de Patrimonio Cultural de la Humanidad, aunque ha contribuido a la protección de la ciudad histórica y el significado y valores del conjunto urbano como una ciudad viva, también ha generado un acelerado crecimiento poblacional y de la mancha urbana, situación que repercute en la aparición del comercio informal, el cambio de uso de suelo de habitacional a comercial, la falta de conservación del Patrimonio edificado de propiedad privada, el ineficiente y conflictivo sistema de transporte y movilidad urbana, incremento del valor de propiedad vinculada a procesos de tercerización y especulativos; manifestaciones públicas y ocupación de las plazas y calles por grupos sociales, dando lugar a conflictos viales, anarquía y vandalismo en el Patrimonio. El conjunto de estos aspectos confirma que los centros históricos continúan siendo espacios de disputa y apropiación por parte de diversos grupos sociales, que los ubica como el sitio de expresión de inconformidades, de demanda y participación social.

Finalmente, es preciso apuntar que esta amplia gama de situaciones también se ven afectadas por la falta de coordinación entre dependencias del gobierno y participación ciudadana para la gestión e implementación de políticas públicas que contribuyan y favorezcan a la mejora y bienestar social, así como a la conservación de monumentos históricos, antes que intereses del sector privado, por lo que resulta evidente la estrecha relación que existe entre las políticas públicas urbanas y la gestión en centros históricos.

\section{Conclusiones}

Los bienes culturales y arquitectónicos de los centros históricos constituyen un foco de atracción tanto para turistas como para inversionistas del mercado turístico debido al potencial cultural, social y paisajístico que presentan. El Centro Histórico de Morelia, no es ajeno a dicha situación ya que por las características físicas, sociales y culturales con las que cuenta, se le ha otorgado el título de Patrimonio Cultural de la Humanidad cuya finalidad principal es la de conservar y mantener su aspecto a través del tiempo para el disfrute de futuras generaciones, pero ha estado sujeto a la especulación por la actividad turística implementada mayormente por el sector privado, situación que confirma la mercantilización del espacio público.

No obstante, antes y después de la declaratoria de la UNESCO, el Centro Histórico de Morelia ha experimentado diversos procesos de intervención urbana, mismos que no son indiferentes al modelo neoliberal aplicado en las ciudades, pues se considera un producto del proceso general de valorización del capital y, en este caso, su valor de uso concentra condiciones de producción y acumulación mediante el consumo de mercancías y su consolidación funcional como atractivo para los visitantes.

De ahí que la problemática de especulación y mercantilización de los Centros Históricos, se consideren un producto de la implementación de políticas urbanas neoliberales a través del negocio inmobiliario y la industria turística, la restitución de tejido social y de rehabilitación urbana, incitando a cambiar la renta y uso del espacio público, principalmente por el sector privado, y dejando de lado las necesidades básicas de la población local y la conservación del legado histórico, tal como lo mencionan Ponce Herrero (2018) y Ormindo de Azevedo (2009). Dicha situación, se deriva de vacíos en los instrumentos jurídicos que regulan tanto el manejo y cuidado del Centro Histórico de Morelia como la implementación de planes y programas en materia de desarrollo económico, social y cultural, por lo que se torna necesario crear esquemas de gobernanza multinivel que involucren a los gobiernos, federal, estatal y municipal, para el ordenamiento y que la política urbana vaya encaminada a acciones de mejoramiento sin que ello afecte el legado de patrimonio y sobretodo en la construcción social del espacio público. 
De esta manera, se considera que los procesos de intervención urbana y desarrollo turístico en Centros Históricos, pueden detallarse en función de su capacidad de acogida y con base a las exigencias de conservación del legado histórico-cultural, además de considerarlos desde una perspectiva compleja, ya que es preciso exaltar el contexto histórico con el objetivo de descifrar los procesos de transformación y cómo es que éstos influyen en la dinámica de realidad urbana actual de estos sitios, dentro de la oferta turística y comercial y la importancia de la ciudad; pues de acuerdo con González-Hernández (2009), Pérez Medina y Torres Pérez (2016), Gil y Briceño (2005), Ortiz et al. (2017) y Ormindo de Azevedo(2009), para erradicar la problemática de mercantilización de estos sitios y el detrimento del patrimonio y el sector social que los habita, se requiere la inclusión tanto de actores públicos como privados que gestionen políticas urbanas de intervención conforme a las necesidades de la dinámica económica, política, social y cultural de los Centros Históricos ya que, si bien el turismo genera recursos económicos que favorecen la conservación del patrimonio, también es fuente de presión ante el flujo excesivo de turistas que traen consigo otras problemáticas como desabasto de alimentos, carencia o contaminación de agua en sitios aledaños y problemas de movilidad vial y peatonal, entre otros.

La incidencia de la intervención urbana en el desarrollo turístico del Centro Histórico de Morelia se ha dado en función de la peatonalización de diversos espacios, cambios en el uso de suelo, cambios de usos residenciales hacia la periferia, la especialización de tipologías comerciales y residenciales basadas en hotelería, restaurantes, centros nocturnos, centros de convención, entre otros, además de generar problemas de tránsito vehicular en el cuadro principal del Centro Histórico, situación que permite afirmar el planteamiento hipotético. Lo anterior, se relaciona con la perspectiva histórica y la visión dinámica de la realidad urbana del CHM, traducida en la mercantilización de dicho espacio bajo las características de la política neoliberal, amenazando la vitalidad de la economía local, la integridad de las edificaciones y la calidad de vida de los habitantes como parte del Patrimonio Cultural y favoreciendo al mercado turístico.

Finalmente, se considera que la estructura física como legado histórico-cultural es el aspecto más representativo del Centro Histórico de Morelia debido a que la intervención urbana propició la rehabilitación y recuperación de diversos espacios y edificaciones que dieron lugar a la declaratoria y a su vez, aumentar su importancia cultural como representante de la memoria colectiva de la sociedad, de tal manera que su impulso siga trascendiendo para el desarrollo de estrategias de conservación a largo plazo, por lo que resulta necesario participar en la construcción de una relación congruente entre los procesos de intervención urbana y el desarrollo turístico ya que, si bien están influenciados por la política neoliberal, también han permitido la recuperación del patrimonio edificado y la generación de recursos económicos, además de mantener viva la ciudad. De esta manera, resulta indispensable generar un marco normativo de gestión urbana y patrimonial, así como para el desarrollo turístico adecuado para el Centro Histórico, en el que se integren los sectores público, privado, social para llevar a cabo nuevos procesos de intervención urbana que asienten un beneficio común [B]

\section{Referencias}

Aguilera Soria, R. (2016). La construcción del significado del Patrimonio Cultural Moreliano (siglos XIX y XX). En Jiménez Izarraraz, M. A. y Bernal Astorga, Y. (Eds.), Morelia, 25 años de ser Patrimonio Mundial (pp. 215234). Zamora, Michoacán: El Colegio de Michoacán, H. Ayuntamiento de Morelia, Universidad Michoacana de San Nicolás de Hidalgo, Secretaría de Cultura de Michoacán.
Armenta, A. (2009). El patrimonio cultural urbano: identidad, memoria y globalización. Andamios. 6(12), 7-10. 
Campos Gutiérrez, J. (2017). La zona patrimonial de la ciudad de Campeche en la era neoliberal. Intervenciones y cambios en el uso habitacional. En Pineda, A. y Velasco, M. (Coord.), Ciudades y Centros Históricos: habitación, políticas y oportunidades (pp. 113-126).

https://www.puec.unam.mx/pdf/publicaciones digit ales/ciudades centros historicos v2 digital.pdf

Carrión, F. (2005). El centro histórico como proyecto y objeto de deseo. Eure, 31(93), 89-100. https://doi.org/10.4067/S0250-71612005009300006

Cejudo Collera, M. (2017). Retos y desafíos para la vivienda en el Centro Histórico de San Francisco de Campeche. En Pineda, A. y Velasco, M. (Coord.), Ciudades y Centros Históricos. Los retos de la vivienda y la habitabilidad (pp. 63-76).

https://www.puec.unam.mx/pdf/publicaciones digit ales/ciudades centros historicos v1 digital.pdf

Cerletti, A. (2017). Vivir en el casco histórico de Buenos Aires. En Pineda, A. y Velasco, M. (Coord.), Ciudades y Centros Históricos. Los retos de la vivienda y la habitabilidad (pp. 77-86).

https://www.puec.unam.mx/pdf/publicaciones digit ales/ciudades centros historicos v1 digital.pdf

CONACULTA. (Consejo Nacional para la Cultura y las Artes). (2017). Morelia. Ciudad Mexicana, Patrimonio Mundial.

https://www.cultura.gob.mx/turismocultural/destino mes/morelia/index.html

Delgadillo Polanco, V. M. (2009). Patrimonio urbano y turismo cultural en la Ciudad de México: las chinampas de Xochimilco y el Centro Histórico. Andamios, 6(12), 69-94. https://www.redalyc.org/articulo.oa?id=6281595700 $\underline{4}$

Filipe Narciso, C. (2013). Urbanismo neoliberal y diseño del espacio público. Revista Legado de Arquitectura y Diseño, (13), 77-92.

http://www.redalyc.org/articulo.oa?id=47794737200 $\underline{6}$

Gil, S. B. y Briceño, A. (2005). Intervención sobre la imagen urbana en Centros Tradicionales. Proyecto de renovación urbana: Funicular-Trolebús, Mérida, Venezuela. Sociología y Antropología, 15(44), 367397. http://www.redalyc.org/articulo.oa?id=70504406
González-Hernández, G. M. (2009). La revitalización del Centro Histórico de Zacatecas y la conciencia social. Economía, Sociedad y Territorio, 9(30), 473-513. http://www.scielo.org.mx/pdf/est/v9n30/v9n30a8.pd f

Gurovich, A. (2002). Intervenciones urbanas: acerca del proyecto urbano. Urbano. 5(6), 62-67. http://www.redalyc.org/articulo.oa?id=19850612

INEGI. (Instituto Nacional de Estadística y Geografía), (2009). Prontuario de información geográfica municipal de los Estados Unidos Mexicanos. Morelia, Michoacán de Ocampo.

Jiménez Izarraraz, M. A., Bernal Astorga, Y., Aguilera Soria, R. \& Romo Careaga, J. A. (2016). Las primeras fotografías de Morelia. En Jiménez Izarraraz, M. A. y Bernal Astorga, Y. (Eds.), Morelia, 25 años de ser Patrimonio Mundial (pp. 347-384). Zamora, Michoacán: El Colegio de Michoacán, $\mathrm{H}$. Ayuntamiento de Morelia, Universidad Michoacana de San Nicolás de Hidalgo, Secretaría de Cultura de Michoacán.

López Valencia, A. P. y López Bernal, O. (2012). Conceptualización de un modelo de intervención urbana sostenible. Ecobarrios en el contexto latinoamericano de reciente industrialización. Revista de Arquitectura, 14. 116-127. http://www.redalyc.org/articulo.oa?id=12512587701 $\underline{4}$

Luna Martello, G. A. (2015). Intervención urbana Barrio Chino / mercado de artesanías Centro Histórico, Ciudad de México. UNAM. http://132.248.9.195/ptd2015/mayo/0729284/Index. $\underline{\text { html }}$

Mercado López, E., (2017). Políticas públicas, patrimonio edificado y población residente del centro histórico de Morelia. En Pineda, A. y Velasco, M. (coordinadores), Ciudades y Centros Históricos: habitación, políticas y oportunidades (pp. 113-126). https://www.puec.unam.mx/pdf/publicaciones digit ales/ciudades centros historicos v2 digital.pdf

Navarrete Escobedo, D. (2017). Tematización turística de los centros históricos y transformaciones del patrimonio construido. En Pineda, A. y Velasco, M. (Coord.), Ciudades y Centros Históricos. Los retos de la vivienda y la habitabilidad (pp. 169-179).

https://www.puec.unam.mx/pdf/publicaciones digit ales/ciudades centros historicos v1 digital.pdf 
Ormindo de Azevedo, P. (2009). El Centro Histórico de Bahía Revisitado. Andamios, 6(12), 95-113.

http://www.scielo.org.mx/scielo.php?script=sci_artte xt\&pid=S1870-00632009000300005

Ortiz Álvarez, M. I., Tamayo Pérez, L. M. O., González Sánchez, J. y Villaseñor Franco, A. (2017). Guanajuato, "Ciudad Patrimonio de la Humanidad". ¿Oportunidad o desafío para el turismo sostenible? Arbor, 193(785), 1-21.

http://arbor.revistas.csic.es/index.php/arbor/article/ view $/ 2210 / 3043$

Pérez Medina, S. y Torres Pérez, M. E. (2016). Nuevos usos y usuarios en la vivienda del Centro Histórico de Mérida, Yucatán. En Balandrano Campos, A., Valero Pié, V. y Ziccardi, A. (Coord.), Conservación y desarrollo sustentable de Centros Históricos (pp. 179207).

https://www.academia.edu/36083600/2017 Nuevos usos y usuarios en vivienda del_Centro Hist\%C3 \%B3rico.pdf

Ponce Herrero, G. (2018). El Centro Histórico de Orihuela (Alicante): de espacio patrimonial a espacio de rentas urbanas. Boletín de la Asociación de Geógrafos Españoles, (76), 183-217. https://dialnet.unirioja.es/servlet/articulo?codigo $=63$ $\underline{88647}$

Rodríguez García, J. L. (2001). Patrimonio cultural y turismo en Morelia. CUADERNOS. Patrimonio cultural y turismo, (14), 81-98.

https://www.cultura.gob.mx/turismocultural/cuader nos/pdf14/articulo6.pdf

Rodríguez, C., Devalle, V. y Ostuni, F. (2013). Ciudades neoliberales: políticas urbanas, diseño y justicia social. Quid 16. Revista del Área de Estudios Urbanos, 3(3).

Sager, T. (2011). Neo-liberal urban planning policies: A literature survey 1990-2010. Progress in Planning, (76), 147-199.

https://www.sciencedirect.com/science/article/pii/SO 305900611000511

SECTUR (Secretaría de Turismo). (2017). Pp S248

Programa de Desarrollo Regional Turístico Sustentable y Pueblos Mágicos "PRODERMÁGICO". http://www.sectur.gob.mx/gobmx/wpcontent/uploads/2014/10/MICH.pdf
Theodore, N., Peck, J. y Brenner, N., (2009). Urbanismo neoliberal: la ciudad y el imperio de los mercados. Temas Sociales, (66), 1-13.

Troitiño Vinuesa, M. A. y Troitiño Torralba, L., (2016). Patrimonio y turismo: reflexión teórico-conceptual y una propuesta metodológica integradora aplicada al municipio de Carmona (Sevilla, España). Scripta Nova Revista Electrónica de Geografía y Ciencias Sociales, 20.

Troitiño Vinuesa, M. A., (1992). Centro histórico, intervención urbanística y análisis urbano. Anales de Geografía de la Universidad Complutense. (11), 2548.

UNESCO. (2017a). ¿Qué es el patrimonio cultural inmaterial? https://ich.unesco.org/es/que-es-elpatrimonio-inmaterial-00003

UNESCO. (2017b). Centro histórico de Morelia. http://whc.unesco.org/es/list/585

UNESCO. (2017c). Patrimonio mundial. http://www.unesco.org/new/es/mexico/workareas/culture/world-heritage/

Zavala García, M., (2016). Transformaciones y pervivencias de los barrios en el Centro Histórico de Morelia. En Jiménez Izarraraz, M. A. y Bernal Astorga, Y. (Eds.), Morelia, 25 años de ser Patrimonio Mundial (pp. 305-323). Zamora, Michoacán: El Colegio de Michoacán, H. Ayuntamiento de Morelia, Universidad Michoacana de San Nicolás de Hidalgo, Secretaría de Cultura de Michoacán.

Ziccardi, A. (2016). Procesos y actores de la planeación participativa en centros históricos de ciudades mexicanas. En Balandrano Campos, A., Valero Pié, V. y Ziccardi, A. (Coord.), Conservación y desarrollo sustentable de Centros Históricos (pp. 45-61). http://ru.iis.sociales.unam.mx/jspui/bitstream/IIS/56 70/2/Procesos\%20y\%20actores.pdf

Zúñiga Bravo, F. (2014). Las transformaciones del territorio y el patrimonio cultural en el Totonacapan Veracruzano, México, basadas en la actividad turística como estrategia de desarrollo regional. Cuadernos de Turismo, (34), 351-372. 